\title{
HISTOMORPHOLOGICAL STUDY OF PAEDIATRIC LIVER TUMOURS-A SINGLE INSTITUTION EXPERIENCE
}

M.Ramani ${ }^{1}$, K.Geetha ${ }^{2}$, O.H.Radhika Krishna ${ }^{3}$, K.Ramesh Reddy ${ }^{4}$,P.Srinivas Reddy ${ }^{5}$, Challa Madhuri6,R.Sowjanya ${ }^{7}$

1. Professor, Department of Pathology, Niloufer Hospital, Hyderabad.

2. Assistant Professor, Department of Pathology, Niloufer Hospital, Hyderabad

3. Assistant Professor, Department of Pathology, Niloufer Hospital, Hyderabad

4. Professor \& HOD, Department of Pediatric Surgery, Niloufer Hospital, Hyderabad.

5. Professor, Department of Pediatric Surgery, Niloufer Hospital, Hyderabad

6. III rd year M.B.B.S, Department of Pathology, Osmania Medical College, Hyderabad

7. Post graduate, Department of Pathology, Niloufer Hospital

\section{CORRESPONDING AUTHOR:}

\section{Dr.M.Ramani,}

Niloufer Hospital Institute of Child Health,

Red Hills, Hyderabad, Andhra Pradesh.

E-mail: drmramani@sify.com

\begin{abstract}
INTRODUCTION: Liver tumours are uncommon in infancy and childhood, accounting to $1-2 \%$ of all paediatric neoplasms. Though rare, $2 / 3 \mathrm{rds}$ of cases unfold as malignancies. These neoplasms differ considerably from their counterparts in the older age group. The present study reflects the Niloufer experience, a well established tertiary referral centre, Hyderabad. AIMS \& OBJECTIVES: To analyze the various paediatric liver tumours, to review the frequency and histopathology of paediatric liver tumours and to review the existing literature on liver tumours of infancy and childhood. METHODS AND MATERIALS: A retrospective analysis of children aged between 8 days and 11 years diagnosed with hepatic tumours was done over a period of 7 years (July 2004-June 2011).The cases were analyzed based on clinical, radiological, biochemical, gross and microscopic findings. RESULTS: Of the 22 cases studied, 16 were malignant tumours of which 11 cases were diagnosed as hepatoblastoma and of the remaining 6 cases, 4 were diagnosed as infantile hemangioendothelioma, 2 as mesenchymal hamartomas. The incidence in males is slightly higher than in females reflected by the ratio of 1.6:1.CONCLUSIONS: The spectrum of liver tumours in paediatric population is different from that of the older age group. From the present study, we can gather that hepatoblastoma by far is the most common childhood hepatic malignancy unlike hepatocellular carcinoma in the adults. This study also throws light on the incidence in different paediatric age group, difference in male to female incidence, clinical presentation and biochemical data.
\end{abstract}

KEY WORDS: Hepatoblastoma, Infantile hemangioendothelioma, mesenchymal hamartoma, pediatric liver tumours 
INTRODUCTION: Owing to their rarity, childhood liver neoplasms are less often studied and the existing literature is based on few large studies done by various paediatric centres. In most of the cases the etiology remains unknown. The liver tumours account for $1-2 \%$ of all solid childhood tumours (3). The histopathology of childhood hepatic tumours guides the treatment, prognosis and forms the main basis for precise diagnosis. Though they are less common among all the childhood cancers, if intra abdominal tumours are considered, pediatric liver tumours stand just next to the more common adrenal neuroblastomas and Wilm's tumour

AIMS \& OBJECTIVES : To analyze the various paediatric liver tumours, frequency of various lesions and to study histopathology of paediatric liver tumours and review existing literature on liver tumours of infancy and childhood

MATERIALS AND METHODS : The present study of paediatric hepatic neoplasms was conducted over a period of seven years i.e, from July 2004 to June 2011 in a well established tertiary paediatric referral centre in India. All the cases diagnosed with liver tumours were reviewed with respect to age, complaints , symptoms and signs, family history, investigations done, study of gross specimens and H\&E stained microscopic slides and the biochemical data. During this study period, 22 cases were analyzed. The cases reviewed were in the age group of 8 days to 11 years. The pathological diagnosis was supported in each case by the clinical and radiological ( CT and MRI scans ) findings.

RESULTS: During the seven year study period, 22 children presented with hepatic tumours. Age range observed was 8 days to 11 years with $81.81 \%$ of cases being diagnosed under the age of 5 years (Table no .1). Male to female ratio was 1.6:1. Out of 22 cases, 6 were benign $(27.27 \%)$ and 16 cases were malignant $(72.72 \%)$. Most common benign tumour observed was infantile hemangioendothelioma (66.66\%). The other benign tumours were mesenchymal hamartomas (33.33\%). Most common malignant tumour observed was hepatoblastoma (68.75\%). Histology of most of these cases was pure epithelial, others were mixed. The other malignant tumours observed were lymphomas, hepatocellular carcinoma and neuroblastoma. (Table no.2)

Abdominal distension was the most common symptom at presentation, 15 cases (59\%) presented with abdominal distension out of which one child had associated icterus. 05 cases (22.7\%) presented with lump / mass abdomen ,01 case with Beckwith -Wiedemann syndrome and 01 case with anemia (Table no.3) .Alpha- fetoprotein levels were elevated in all 11 patients of hepatoblastoma .Seven patients had levels $>1000 \mathrm{IU} / \mathrm{ml}, 3$ patients had levels between $500-1000 \mathrm{IU} / \mathrm{ml}$ and 1 patient had levels $<500$ IU/ml. Table no.4 
DISCUSSION: Spectrum of paediatric hepatic tumours is different from adult hepatic tumours .Inferences from the present study are that most of the paediatric liver tumours are malignant, with a slight male preponderance, with median age of presentation at 6 months ,commonest symptom at presentation being abdominal distension. Commonest benign lesion was infantile hemangioendothelioma. Commonest malignant lesion was HEPATOBLASTOMA .The results of the present study have been compared to existing studies in Table no.5 and the results are in concordance.

Reviewing the literature, it is found that there is remarkable diversity of benign tumour masses in children. Hepatic vascular tumours (HVT) which include haemangioma, infantile haemangioendothelioma and arteriovenous malformation (6) were found to be commonest benign liver tumours in children as in our study and are frequently associated with high output cardiac failure. However, Coronado and Angulo ( 8 ) in Mexico found mesenchymal hamartoma to be the commonest benign tumour whereas in Iran, equal frequency of vascular tumours and mesenchymal hamartoma was observed. Nearly $90 \%$ of infantile hemangioendotheliomas are diagnosed in the first 6 months of life, and one-third are diagnosed within the first month. They are rarely discovered after 1 year of age, and biopsy is indicated for older patients to exclude malignant tumours. There is an increased prevalence in patients with hemihypertrophy and Beckwith-Wiedemann syndrome. Individual tumour size varies from 0.5 to $14 \mathrm{~cm}$ in maximum dimension. On cut sections, the mass varies from red-brown and spongy to tan-white and firm. Central areas of hemorrhage, necrosis, fibrosis and gritty calcifications are seen Microscopically tumour comprises of vascular spaces lined by plump endothelial cells and surrounded by fibrous stroma.

Mesenchymal hamartoma of the liver is the second most common benign liver mass in children after infantile hemangioendothelioma. The gross appearance varies from predominantly cystic to solid. In the series of 30 cases described by Stocker and Ishak ( 1,2 ) $83 \%$ of tumours was grossly cystic. Those without cysts tend to be found in younger patients $(1,2)$ The cystic areas of the mass contain a clear amber coloured fluid or gelatinous material . Microscopically tumour shows compressed, branching ductules surrounded by loose mesenchyme.

Malignant liver tumours account for slightly $>1 \%$ of all paediatric malignancies. Epithelial ( hepatocyte-derived) tumours are more common than those of mesenchymal origin. In a study of 716 cases of paediatric liver tumours submitted to the Armed Forces Institute of Pathology between 1970 and 1999, Ishak et al (1) found that the most common malignant tumour was hepatoblastoma, as was in our study. The incidence of these rare liver tumours has been on a rise over the past few year. The cause for this increased incidence is not known, but the survival of very low birth weight premature infants, which is known to cause hepatoblastoma might contribute to the rise in incidence. Some children are at an increased risk because of genetic diseases like Beckwith -Wiedemann syndrome, Gardner syndrome, familial adenomatous polyposis and trisomy 18. Though this is one of the risk factors, consistent association of these genetic conditions with paediatric liver tumours has not been established. Hepatoblastomas occur more commonly in males than in females. 
Hepatoblastomas are composed of cells resembling fetal and neonatal liver , hence the classification as an embryonal tumour. Hepatoblastoma is diagnosed in very young children with a peak in the new born period reflecting that these tumours may develop prenatally.Most commonly, these tumours present in the right lobe of the liver. Histologically, these tumours can be divided into epithelial or mixed (epithelial / mesenchymal ) types. Approximately 5\% of hepatoblastomas are of small cell undifferentiated type associated with a worse prognosis.

The next common malignant lesion hepatocellular carcinoma occurs in older children (10-14 year) and more commonly affects boys. In many Asian countries, HCC in children is 10 times more common than North America. This is related to high incidence of perinatally acquired hepatitis. Bilobar and multifocal disease is more common (12) and survival is below 30\%.

The management generally depends on the staging and involves surgery and neoadjuvant chemotherapy to downsize and downstage the tumour and occasionally liver transplantation. Paediatric liver tumours in particular hepatoblastoma has seen tremendous therapeutic advances over recent years. This has been achieved through advanced radioimaging techniques and refined histopathological studies which have led to improved pretreatment tumour staging and hence better therapy

CONCLUSION: The spectrum of tumours in liver varies considerably in infancy and childhood. Unlike the adult scenario where the most common hepatocellular carcinoma develops with known etiology (e.g. Viral hepatitis), there is very little known etiology of the more common hepatoblastoma in paediatric age group . Our present study over a period of seven years re-affirms the fact that hepatoblastoma remains the most common hepatic malignancy in infancy and childhood .The study also emphasizes on the importance of clinical presentation , median age at presentation and evaluation of raised titres of serum alpha fetoprotein levels in hepatoblastoma .

\section{REFERENCES:}

1. Ishak KG, Goodman ZD, Stocker JT. Tumours of the liver and intrahepatic bile ducts. Washington DC, Armed Forces Institute of Pathology, 2001; 9-48

2. StockerJT et al, Hepatic tumours in children. Clin liver Dis. 2001;5(1),259-81

3. Bita et al : Pathology of paediatric liver tumours, a single centre experience from south of Iran .Indian journal of Pathology and Microbiology : 2010 Volume : 53 Issue : 3 : 422-426

4. Farahmand et al : tumours of liver-a ten year study in children medical center . Tehran university medical journal .May 2007 Vol 65 , no-2,,52-56.

5. Samuel et al :Hepatocellular Carcinoma and Liver Tumours in South African Children . American Cancer Society. 2004; 101:642-9.

6. Prokurat A, Kluge P, Chrupek M, Ko?ciesza A, Rajszys P. Hemangioma of the liver in children: Proliferating vascular tumour or congenital vascular malformation. Med Pediatr Oncol 2002; 39: 524-9. 
7. Maitree et al :Primary Malignant Hepatic Tumours in Children: Fourteen-year Experience with 50 Cases. The Thai journal of surgery 2002; 23:53-60

8. Coronado Perez H, Angulo Herhandez O. Liver neoplasms in children : Bol Med Hosp Infant Mex 1981; 38: 723-40.

9. Walter et al Primary Liver Carcinoma Arising in People Younger Than 30 Years : Am Journal Clin Pathol ; $2005 ; 124: 512-518$

10. Masood et al hepatic Mesenchymal Hamartoma Arch Pathol Lab Med. 2006; 130 : 1567-1569.

11. Stringer MD. The role of liver transplantation in the management of paediatric liver tumours. Ann R Coll Surg Engl 2007; 89: 12-21

12. Singh et al Hepatoblastoma: Experience from a single center 2010 ; Volume : 47 Issue -3: $314-316$

TABLE No. 1: AGE DISTRIBUTION

\begin{tabular}{|c|c|}
\hline AGE AT PRESENTATION & NUMBER OF CASES \\
\hline 8 days -1 year & 10 \\
\hline$>1-5$ years & 07 \\
\hline$>5-11$ years & 05 \\
\hline
\end{tabular}

TABLE No.2: CLASSIFICATION OF LIVER TUMOURS

\begin{tabular}{|l|c|}
\hline \multicolumn{1}{|c|}{ BENIGN TUMOURS } & $\begin{array}{c}\text { No. of } \\
\text { cases }\end{array}$ \\
\hline 1)Infantile hemangioendothelioma & 04 \\
\hline 2)Mesenchymal hamartoma & 02 \\
\hline TUMOURS & \\
\hline 1)Hepatoblastoma & 11 \\
\hline 2)Lymphoma & 03 \\
\hline 3)Hepatocellular carcinoma & 01 \\
\hline 4)Neuroblastoma & 01 \\
\hline
\end{tabular}




\section{ORGINAL ARTICLE}

TABLE No.3: CLINICAL PRESENTATION

\begin{tabular}{|l|c|}
\hline \multicolumn{1}{|c|}{ CLINICAL FEATURES } & $\begin{array}{l}\text { No. Of } \\
\text { cases }\end{array}$ \\
\hline Abdominal distension & 14 \\
\hline Lump / mass abdomen & 05 \\
\hline $\begin{array}{l}\text { Abdominal distension + } \\
\text { icterus }\end{array}$ & 01 \\
\hline $\begin{array}{l}\text { Beckwith -Wiedemann } \\
\text { syndrome }\end{array}$ & 01 \\
\hline Anemia & 01 \\
\hline
\end{tabular}

TABLE No: 4

\begin{tabular}{|c|cc||}
\hline $\begin{array}{l}\text { ALPHA FETOPROTEIN } \\
\text { OF HEPATOBLASTOMA }\end{array}$ & & No. of cases \\
\hline LEVELS(IU/ml)) & & 07 \\
\hline$>1000$ & & 03 \\
\hline $500-1000$ & \multicolumn{2}{c||}{ PATIENTS } \\
\hline$<500$ & \\
\hline
\end{tabular}

TABLE No.5 - COMPARATIVE ANALYSIS OF VARIOUS STUDIES ABOUT PAEDIATRIC LIVER TUMOURS

\begin{tabular}{|l|l|l|l|l|}
\hline \multicolumn{1}{|c|}{ STUDIES } & $\begin{array}{l}\text { Bita et al } \\
(2010)\end{array}$ & $\begin{array}{l}\text { Maitree et al } \\
(2004)\end{array}$ & $\begin{array}{l}\text { Samuel et al } \\
(2002)\end{array}$ & Present study \\
\hline No. of cases & 53 & 64 & 194 & 22 \\
\hline Age group & $<18$ yrs & 1 month-5 yrs & $0-11$ yrs & 8 days-11 yrs \\
\hline Study period & 5 yrs & 14 yrs & 15 yrs & 7 yrs \\
\hline Non-neoplastic & 17 & 14 & --- & 6 \\
\hline Neoplastic & 36 & 50 & 194 & 16 \\
\hline $\begin{array}{l}\text { Most common } \\
\text { tumour }\end{array}$ & Hepatoblastoma & Hepatoblastoma & Hepatoblastoma & Hepatoblastoma \\
\hline
\end{tabular}

*reference from respective studies $(3,5,7)$ 


\section{ORGINAL ARTICLE}

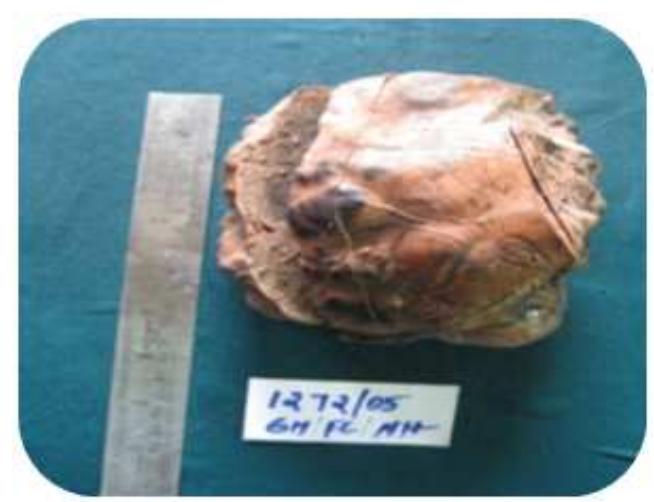

FIGURE 1 : RESECTED SPECIMEN OF HEPATOBLASTOMA, Surface is irregular and grey brown.

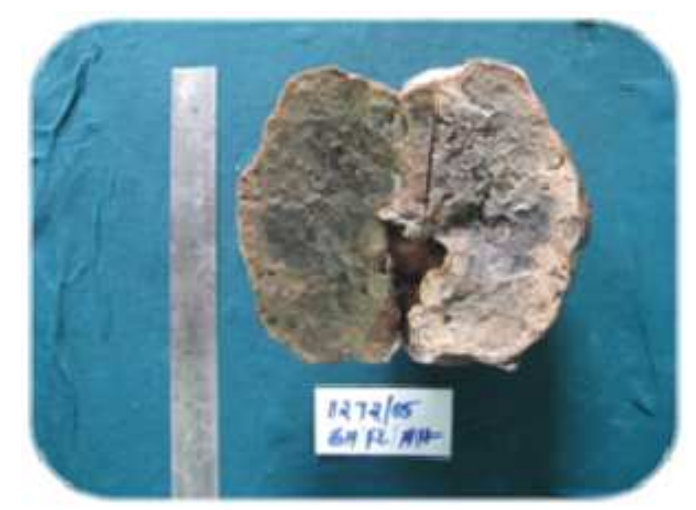

FIGURE 2: CUT SECTION OF HEPATOBLASTOMA Cut section is tan brown, shows hemorrhagic areas.

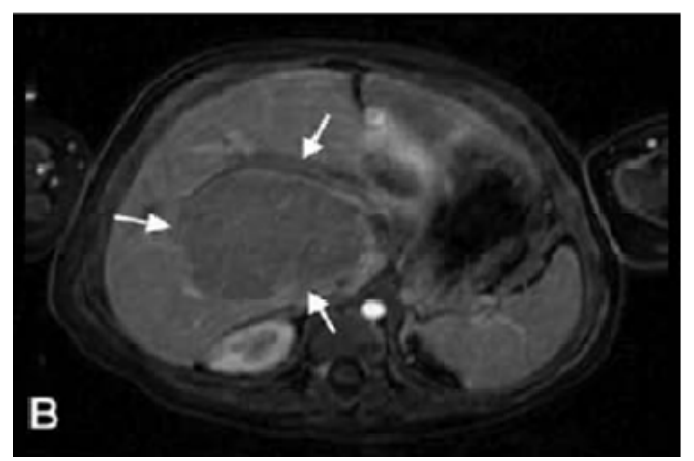

FIGURE 3: MRI SCAN OF HEPATOBLASTOMA Shows heterogenous mass of high T2 signal, with peripheral enhancement 


\section{ORGINAL ARTICLE}

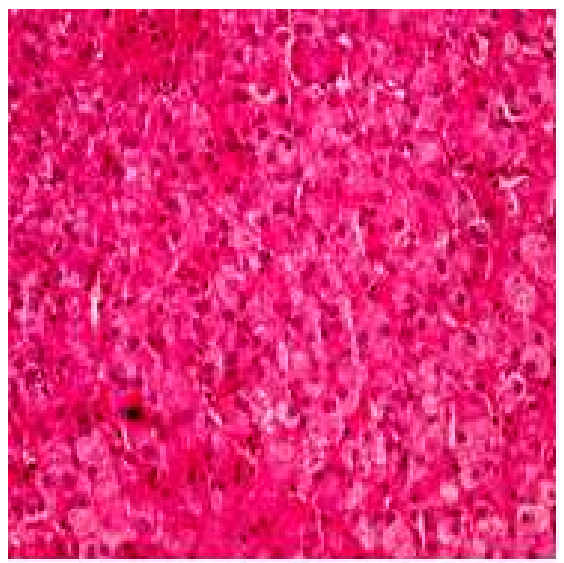

FIGURE 4: MICROSCOPIC PICTURE OF HEPATOBLASTOMA Embryonal type of hepatoblastoma; H\&E stained, 40X

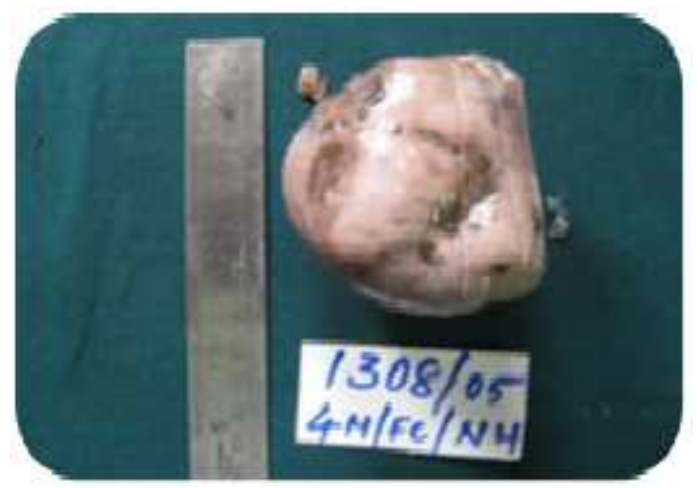

FIGURE 5: RESECTED GROSS SPECIMEN OF INFANTILE HEMANGIOENDOTHELIOMA Surface is irregular

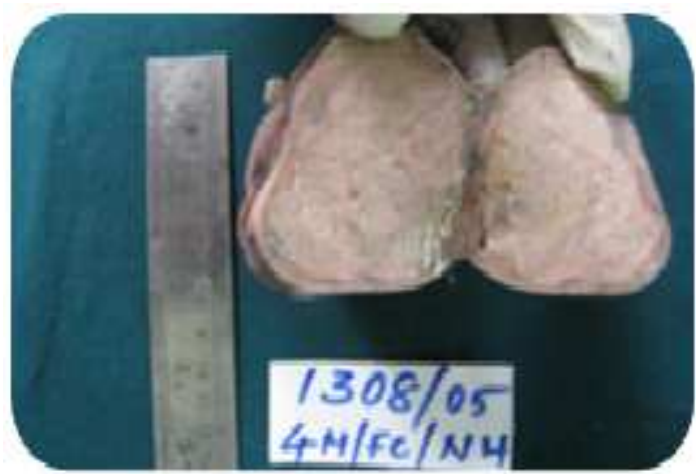

FIGURE 6: CUT SECTION OF INFANTILE HEMANGIOENDOTHELIOMA Cut section is grey tan. 


\section{ORGINAL ARTICLE}

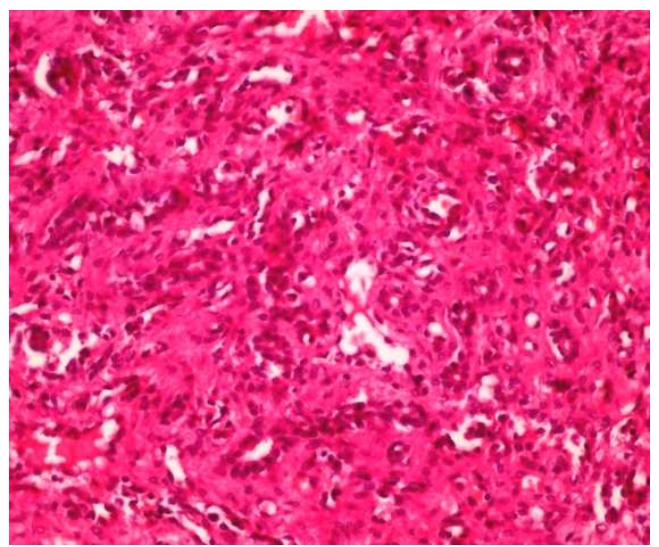

FIGURE 7: MICROSCOPIC PICTURE OF INFANTILE HEMANGIOENDOTHELIOMA Microscopically tumour shows vascular spaces lined by plump endothelial cells surrounded by fibrous stroma; H\&E stained , 40X 